\title{
Topical directions of didactics development in the XXI century
}

\author{
Elena Ivanova ${ }^{1}$, Mikhail Klarin ${ }^{2}$, and Irina Osmolovskaya ${ }^{2, *}$ \\ ${ }^{1}$ Yaroslavl State Pedagogical University named after K. D. Ushinskiy, Respublikanskaya Str., 108/1, \\ 150000 Yaroslavl, Russia \\ ${ }^{2}$ Institute for Strategy of Education Development of Russian Academy of Education, Zhukovskiy \\ Str., 16, 101000 Moscow, Russia
}

\begin{abstract}
The paper analyzes challenges of modern society affecting changes in education that determines the current directions of didactics development. The authors establish that in didactics there are: 1) expansion of the set of objects studied by didactics (the study of general secondary education is supplemented by the study of higher, corporate, family education, education of students with different educational needs), consideration of the learning process in the context of digitalization; 2) the development of methodological approaches to didactic research (activation of empirical research, an increase in the role of research methods of the humanities in didactics, setting the task of developing evidence-based learning research); 3) activation of interdisciplinary research in education (consideration of didactic objects from the standpoint of related sciences didactics, psychology, cognitive science, sociology). The paper consideres conceptual provisions in the development of didactics of higher education.
\end{abstract}

\section{Introduction}

Didactics develops like any science. It deals with a learning process as an object of research. The learning process is specially designed and created in pedagogical reality and develops under changing in social and cultural conditions and updating the requirements for graduates. Didactics answers the challenges of time and develops laws, principles, content of education, forms, methods, technologies for the modern learning process.

How does modern learning differ from what was implemented in the last century? First, the need for lifelong learning, but not for education for life, put forward the importance of the ability of students to acquire knowledge independently - the self-learning ability. Second, the ability to learn requires a change from the traditional "knowledge" approach to the activity-based approach. The main activity in training becomes the activity of students with the pedagogical support of the teacher. Third, the learning process is unfolding in the digital environment and requires the formation of new skills of students: the possession of tools for working in a digital environment; the search, processing, and assignment of information, the ability to distinguish reliable scientific information from fake news, not confirmed by scientific data. Trends in the growing impact

\footnotetext{
* Corresponding author: osmolovskaya@instrao.ru
} 
of a digital environment on learning lead to an increased role for distance education, mixed learning. Fourth, a person in life and professional activity more and more often has to solve complex, non-standard problems, therefore, the problem of developing the creativity of students faces the school, universities, and all educational institutions. Fifth, many tasks in the professional sphere are solved by the team, so the importance of group work in training increases.

Modern trends in education include the personalization of learning:

- a creation of personalized learning trajectories for students ";

- "out-of-school learning", i.e., the exit of the learning process beyond the school, into society, the acquisition of knowledge by students in financial, medical, cultural institutions";

- "big ideas" in the content of education- the emphasis on the use of cognitive methods in learning, "gamification", i.e., using games in the learning process, and others [1].

All this raises the question of developing a "new didactic." The pedagogical literature offers two solutions to this issue:

1) It is necessary to develop completely breakthrough didactic ideas, since, figuratively speaking, improving the kerosene lamp, it is impossible to get an electric lamp [2].

2) Didactics should be developed, but on a solid basis of classical and non-classical didactics, without abandoning what has been developed over the years [3-4].

\section{Materials and methods}

The article outlines the current trends in the development of didactics. The paper analyzes scientific publications of domestic and foreign authors on promising directions of the development of didactic knowledge. The authors used general scientific methods of analysis, comparison, classification, and modeling as research methods.

\section{Results and discussion}

As a result of the study, we concluded that the main directions for the development of didactics are:

1) expanding the set of objects studied by didactics;

2) developing methodological approaches to didactic research;

3) enhancing interdisciplinary research in education.

Consider these three directions. Traditionally, the object of studying didactics was the process of studying in a secondary school. Later, as a result of the differentiation of science, the didactic of higher education, the didactic of preschool education began to develop. Currently, the field of view of didactics includes issues of corporate education, family education, the education of people of "silver age." Note that the learning process as an object of learning didactics in these types of education is built differently. In some cases, it is not didactic laws that are based on, for example, managerial, socio-cultural. But in each case, the learning process can be described from the point of view of didactics, which didactics will have to do. Let us draw attention to the fact that we are expanding the subject of didactics. Now it is not a narrow learning process, but a process of education. If we take into account the understanding of education as integration of education and upbringing, we can record an increase in attention to the personal side of learning (awareness by students of personal meanings, their own values, solving problems of relationship with other students, solving moral problems).

The expansion of the objects of study by didactics is associated with training students who differ in age, educational needs, psychological and health characteristics.

There is a field of research in didactics related to information technology, Internet learning, distance, and mixed learning. It is "digital didactics" or e-learning didactics [5]. 
We talk about the use of cloud technologies in the training process increasingly frequently. That is global systems for collecting, distributing, processing, and using information; Internet of Things (IoT) - a physical, technical, and technological environment of information transmission; Smart Environments is a "reasonable environment" that can become the basis of motivated and self-governing individual education [6].

Mixed learning is not significant news in the educational practice of the last two decades. It consistently attracts the attention of researchers [7-8]. The forced transition to total distance learning in secondary and higher education has become a noticeable phenomenon of the Covid-19 pandemic. Researchers have empirically recorded the trend of" domestication " of the educational process [9]. However, didactic studies of the transformation of learning in forced conditions have started recently [10].

With the development of cognitive sciences that study the process of cognition, the field of cognitive-didactic research has emerged, revealing the possibilities of building learning on the developments made in cognitive science [11-13].

Thus, it is possible to identify areas of expansion of the objects of didactics research related to new tools of the learning process.

Let us consider in more detail such an area of didactic science as the didactics of higher education and show the current directions of its development. It has been developing for a long time in line with the general didactic theory. It has all its essential features and components and uses the classical categorical-conceptual apparatus. Differentiation of science, object, and research subjects led to understanding the need to consider the learning process in higher education, its principles, content, methods, results as special pedagogical phenomena. They are associated with a given provision of goal achievement, peculiarities of interaction between participants in the educational process, conditions, and context of implementation. The dynamics of this process are considered in detail by N.S. Makarova. Nowadays, the development of the didactics of higher education is associated with the postnonclassical scientific paradigm and the idea of the educational process at the university as a complex self-developing system [14].

The existing economic, social, and cultural conditions, the public order for people with higher education primarily set the specifics of this field. These people must have not only professional competencies but also general cultural and personal qualities, which are not directly related to a specific activity but ensure their subjective position in the transformation of the world and themselves. This will allow a graduate to be successful in any changes in requirements of the labor market. They should be prepared to independently plan and implement a continuous purposeful cognitive process, to search for the necessary knowledge, and to manage it for solving professional and personal tasks [15].

The higher school operates in conditions of rapid variability of the demanded professional characteristics of a future graduate, an avalanche-like growth of information flows associated with his further work. At the same time, education should be built taking into account social and personal ideas about the quality and content of professional knowledge and skills in a particular field of activity, since they are transformed into requirements for learning outcomes. Nowadays, the university is implementing a competency-based approach. In the most general view, competence is the ability and willingness to use existing knowledge to solve practical situations in the course of professional activity. The third generation of Federal State Educational Standard of Higher Education (FSES of HE $3++$ ) is based on dynamically set universal competencies that allow realizing the continuity of education at all levels of higher education (bachelor's master's - postgraduate studies). All competencies include the student's activity as a selfchanging subject of professional education. Otherwise, only the activity component remains of them, and education in higher education returns to the traditional assimilation of knowledge-skills-abilities. 
In this regard, to single out a student himself as one of the objects of research is relevant for the didactics of higher education. He is a key participant in the educational process and the purposeful development should be focused on the entire educational process. At the same time, it is necessary to focus on his value system, general cultural level, social, professional, and personal orientation.

Such an expansion of the study of didactics requires considering the process of higher education as an educational environment. There is also a need for considering conditions for the realization of potential opportunities, professional and personal needs of students, determining the self-realization and self-improvement of students. In this regard, the terminological apparatus of didactics includes such concepts as "subject", "subjectivity", and "personal potential". One associates the subjective position with a person's ability to be a source and at the same time a fruit of his own activity. Subjectivity predetermines the individual's ability to transform his life activity into a conscious object of practical transformation. The personal potential of participants in the educational process is viewed as the potential for self-regulation, a system of individual differences associated with its success [16].

The development of a learning process focused on the self-development and selfactualization of a student during higher professional education involves, first of all, the establishment of leading didactic principles. These principles determine the most general requirements for the organization of the learning process and set its direction. Such principles include:

- the creation of a developing educational environment, which on the one hand should be professionally oriented and its conditions should be close to future professional activities, and on the other hand ensure the problematization of education, linking students with culture, encouraging them to change themselves, to the transition from learning to selfeducation;

- variability of educational content, learning process, and performance. This principle is based on free choice, taking into account the individual contribution of each student to the result;

- the interactivity of education, which is associated with the availability of feedback constant reporting to a student about his progress in studying the material, his mistakes, and which points should be paid special attention to. This principle implies the creation of a field of pedagogically expedient interaction between educational subjects. The quasi-entity may be a multimedia training program;

- reflexiveness of learning, aiming students at constant self-esteem and selfdetermination in cognitive, personal, and social relations. The result is a rethinking by a person of himself and relations with the world, an assessment of the success of moving towards a strategic goal. The subject position of students when setting (or adopting) the aim of the activity is an important point of disclosure of this principle;

- support of productive learning, during which the student creates an individual educational product. The reflection of the value and meaning content of the activity in the result is very important. For monitoring of educational product's creation can use forming evaluation.

This totality of didactic principles is not exceptional and complete. The didactic understanding of the process of integral continuous formation of the personality as a specialist and a professional needs further research. This means ensuring a person's dynamic entry into the professional environment, mastering professional experience, forming a readiness for self-realization, self-improvement, and continuous professional development.

The implementation of these principles requires the creation of a qualitatively new educational space and the corresponding support of the process. It is necessary to design a 
complete process of learning, taking into account all its components. The procedure for evaluating the results is of particular importance. It should include dynamic self-monitoring and self-assessment. The emphasis shifts to strengthening the student's independence as a subject of education, activating his cognitive activity through the formation of a need for self-education, and developing the ability to self-regulate. In this case, these ensure the selfdetermination of students in the world of knowledge, gaining experience in the field of education, the professional position in relation to themselves as a subject of education. The idea of the value of teaching for professional and personal development, about building your own life strategy becomes significant.

Anthropological and subjective-personal approaches that allow for professional and educational targeting, planning and reflection in relation to the learning process and in relation to oneself; methods and technologies involving individual creative activity, acquisition and protection of position (project training, problem training, case-stages, pedagogical workshops, quests, etc.), self-assessment, mutual assessment, interactive (programmatic) assessment, as well as reflections (joint projects, group work, discussions, debates); use of information technology resources, in particular mixed training, quizzes, blogs, online encyclopedias, online courses (v.h. MOOC), discussion platforms, online games and simulators, Learning management systems (LMS) in general; productive subject-subject interaction, organizing, accompanying, supporting the position of the teacher in combination with readiness for self-change, with the understanding that students may have additional information, be more aware of some issues can act as didactic tools for implementing the above provisions.

It implies, in particular, the question of the correlation of various forms of organization of education - lectures, seminars, practical and laboratory work, various practices with independent work of students, both in content and in procedural aspects.

It is possible to note that nowadays in a higher education institution the main didactic relation "a teacher - a content of education - a student" assumes an active position of both subjects of the educational process, increase in the importance of the subject and personal knowledge, a possibility of a variable way and results of student's mastering of training material. Content of education appears at students as information space which he masters by means of the teacher according to the needs and orientation of a person. The educational process becomes non-linear, open, self-developing, multifunctional, thereby allowing students to realize themselves in the space of professional and personal perspectives.

Let's look at differences in the methodology of didactic research. Justification and verification of new didactic knowledge were initially carried out by logical reasoning, drawing analogies with other phenomena (recall Ya. A. Komensky). Experimental work, observation of students, studying the products of their activities, conversations, and questionnaires begin to play an increasingly important role. In the ratio of qualitative and quantitative methods, priority is given to qualitative methods. The development of didactics in the middle of the last century took place in the context of scientism, when the natural sciences, in particular, physics, are considered the ideal of any science. The question is raised about didactic experiments that, if repeated by other scientists, would give exactly the same result. Since such experiments are not carried out, there is a statement that didactics is not a science, it is spiritual and practical knowledge [17].

The experiment in the social and humanities sciences, to which didactics also belongs, is different from the experiment in the natural sciences. The person is an extremely complex object of study. In any pedagogical phenomenon, there is an impact of a large number of factors, not all of which can be recorded and identified.

Gradually the influence of scientism on didactics decreases in the era of non-classical development of science, distinct understanding of the same objects is allowed, respectively, the presence of different definitions of the same concept. The idea of building different 
variants of the learning process, the effectiveness of which is different in divergent conditions, appears and is confirmed in practice. For example, the construction of the learning process in the competence approach differs from the construction in the traditional "knowledge" approach. If the assessment of the results of the competence approach is based on the performance indicators of the "knowledge" approach, we will come to the conclusion that this approach is not effective. The components of the learning process (the goal, content of education, methods, forms, results) are different from other approaches. The understanding that didactics is a social and humanitarian science leads to the expansion of the assortment of research methods: their palette is enriched with narrative conversations, interviews, monographic descriptions of processes, phenomena, and changes occurring in the inner world of students. Methods of psychological and sociological research are more widely used.

Empirical studies of education are expanding. As an example of such a study, we will cite the study of the National Research University "Higher School of Economics". "Factors of attrition of engineering students in Russian universities". This study examines the phenomenon of student dropout. The study aims to establish the relationship between the dropout of students, their academic involvement, and the level of academic skills. Conducting empirical research allows us to establish scientific facts and identify the relationships between them.

Let us pay attention to the development of trends in evidence-based pedagogy, which is developing as a basis for decision-making in the field of education [18].

There are research- projects along with classical research carried out according to the scheme: the search and formulation of the problem, the justification of its relevance, the characterization of the degree of development of the problem, the formulation of the object and subject of research, goals, hypotheses, and tasks. Note that the traditional classical research is necessarily carried out in a certain theoretical framework, relies on provisions already known in science. The research, as a rule, creates a theoretical model of the studied process, reveals the conditions for its implementation.

The creation of innovative practice is a central link to a research-project. While general ideas about the conceptual foundations, patterns of practice development, methods, and forms of innovative construction of the learning process exist in an insufficiently specific form at the beginning of the study. $\mathrm{n}$ the course of the development of the research project, the specification of the initial positions of practice, the identification of the patterns of its functioning occurs, metaphorically speaking, "from the wheels." An example of such a research project is the development of a conceptualized practice of tutoring, carried out by a research team led by T.M. Kovaleva.

Recently, the emphasis has been placed on interdisciplinary and multidisciplinary learning research. Note that didactics uses, scientific data obtained in other sciences (for example, psychology, sociology, cultural studies) in polydisciplinary studies. In fact, didactics has always been a multidisciplinary science. New knowledge opens up in this research by representatives of various scientific disciplines (or specialist who masters perfectly two scientific fields, for example, linguistics and didactics). The obtained new knowledge belongs to the sciences participating in the study. An example of such a study is the psychodidactic project "Mathematics. Psychology. Intelligence" based on the psychological ideas of M.A. Kholodnaya was designed a model of teaching mathematics in 5-9 forms. E.G. Gelfman developed a didactic model in his study, which was provided with methodological tools, in particular, textbooks. The performance of the model was tested, both by didactic and psychological methods. They tested the assimilation of knowledge, the formation of skills and skills in the field of didactic results. They investigated parameters of intellectual activity: intellectual efficiency, an individual peculiarity of intellectual activity, creativity, intellectual reflection in the field of psychology [19]. 


\section{Conclusion}

Thus, the new educational contexts of lifelong education determine the number of current trends in the development of didactics:

- Research on schooling in special settings (mixed education, fully distance learning, including compulsory distance learning, hospital education, coaching, family/home education)

- Research on learning in the context of supplementary education (children and youth, adults, people of "silver age")

- Research on training in the context of vocational education (business education, corporate training, and development, alternative non-institutionalized formats of additional vocational education)

In a special study, we highlighted "cross-cutting didactic issues" that relate to learning at all levels of the educational ladder, a wide range of educational practice contexts. These include psychological and didactic characteristics of a modern subject of learning; the didactic basis for selecting the content of education in the context of the transformation of the educational environment of the digital age; expansion of conceptual and terminological apparatus of didactics; contextual features of didactic principles in each area of educational practice; tasks and functions of non-traditional learning formats (e.g. project, inverted, mixed learning); didactic foundations and range of roles of a teacher, development of didactics of teacher training [20].

In general, the current directions of didactic research are determined by:

- New types of educational contexts in which training takes place;

- New approaches to research methodology, including highlighting cross-cutting areas of didactic research;

- New training tools.

\section{Acknowledgements}

The publication was prepared as part of scientific project No. 20-013-00248 "Promising directions of didactic research in Russia" supported by the Russian Foundation for Basic Research.

\section{References}

1. M. Gasinets, N. Avdeenko, A. Mikhailova, O. Fedorov, T. Pashchenko, Great ideas for educational content (2020)

2. S. Ivanova, Education and Society, 4 (2017)

3. M. Klarin, Russian Education \& Society, 58 (2016)

4. I. Osmolovskaya, Didactics: from classics to modernity (2020)

5. M. Tchoshanov Engineering of Learning: Conceptualizing e-Didactics (2013)

6. O. Rybicheva, Bulletin of Vyatka St. Univ., 4 (2019)

7. A. Margolis, Psych. science and Education, 23 (2018)

8. N. Andreeva, Mod. foreign psychol., 9 (2020)

9. B.Williamson, R.Eynon, J.Potter, Learning, Media and Technology, 45 (2020)

10. Home school work of schoolchildren: ways of improvement: Materials of the International Scientific and Practical Conference (2020) 
11. S. Kostromina, N. Bordovskaya, N. Iskra, O. Chuvgunova, D. Gnedykh, D. Kurmakaeva, Neurosc., Psych. \& Ed.: Prob. \& Prosp. of Interdisc. R., 36 (2015)

12. M. Apaydin, M. Hossary, Int. J. of Educ. Manag., 31 (2017)

13. M. Klarin, Domestic and foreign pedagogy, 1 (2017)

14. M. Makarova, Didactics of the Higher School: the classical foundations for post-nonclassical perspectives (2011)

15. Z. Zhu, Knowledge Manag. Res. \& Prac. 2 (2004)

16. D. Leontiev,Educational policy, 3 (2019)

17. I. Logvinov, Actual problems of modern didactics (polemic reasoning, (2013)

18. A.Margolis Psychological Science and Education, 25 (2020)

19. E. Gelfman, M.Kholodnaya, Psikhodidaktika shkolnogo uchebnika: ucheb. manual for universities (2019)

20. M. Klarin, I. Osmolovskaya, Education and science, 22 (2020) 